\title{
Assessment of inpatient antibiotic use in Halibet National Referral Hospital using WHO indicators: a retrospective study
}

Nebyu Daniel Amaha ${ }^{1 *}$, Yohana Haile Berhe ${ }^{2}$ and Atul Kaushik ${ }^{1}$

\begin{abstract}
Objective: Inappropriate use of antibiotics in primary care and hospital settings is a major contributing factor to the spread of antibiotic resistance. Many microorganisms were tested in Eritrea and have proven resistant to ampicillin. The aim of this study was to investigate the prescription pattern, hospital indicator and patient care indicator of antibiotics among hospitalized patients in Halibet National Referral Hospital, Asmara, Eritrea.

Results: The data on prescription patterns showed $79 \%$ of hospitalizations had at least one antibiotic prescribed and on average 1.29 antibiotics were prescribed per hospitalization; prescribing using generic name was at 97\%; all (100\%) of the antibiotics were prescribed from the Eritrean National List of Medicines. On average an antibiotic was prescribed for 6.36 days $(S D=6.06)$. Ampicillin was the most commonly prescribed antibiotic $(42.1 \%)$ and parenteral was the most common route prescribed (81.4\%). The data on hospital indicators showed key antibiotics were out of stock on average for 78.18 days; $87.5 \%$ of key antibiotics were available on the day of the study. The data on patient care indicator showed patients taking antibiotics stayed in the hospital for 9.97 days ( \pm 7.33 days).
\end{abstract}

Keywords: Antibiotic, Rational drug use, WHO indicators, Inpatient study, Prescription

\section{Introduction}

Irrational use of antibiotics in inpatient settings is an important issue that needs attention. Some causes for inappropriate drug use in hospitalized patients are; unnecessary use of antibiotic, inadequate regulation and monitoring, inappropriate dose, and multiple antibiotic prescribing [1-4]. Lack of Standard Treatment Guideline (STGs), protocols for rational drug use, and weak or absent Drug Therapeutic Committees (DTCs) exacerbate the inappropriate antibiotic use [5]. About 70\% of hospital-acquired bacterial infections are resistant to at least one antibiotic [6].

WHO has developed key indicators to measure antibiotic use in health facilities [7] and many studies [8-16] have reported using the WHO indicators. These indicators also known as "core drug use indicators" include

\footnotetext{
*Correspondence: nebyudan@gmail.com

1 School of Pharmacy, Asmara College of Health Sciences, 118-Adi Shimagle, P.O. Box 8566, Asmara, Eritrea

Full list of author information is available at the end of the article
}

prescribing, hospital and patient-care indicators were developed to be used at primary healthcare facilities and later adapted to tertiary hospitals [4] (Additional file 1: Annex S3). However, these indicators do not address factors like duration of hospital stay or the type of disease being treated which could influence antibiotic use [17]. Thus the outpatient focused WHO core drug use indicators were modified to the inpatient settings.

High rate of antibiotic use has been reported in Eritrea [18], however, published research on antibiotic use in Eritrean hospitals is meager [19]. The hospital indicators focus on studying the availability and stock outs of key antibiotics. A key antibiotic for the purposes of this study is a drug having a " $\mathrm{V}$ " (vital drug) designation in the ENLM and that is used at a hospital level. Vital medicines are defined as life-saving, crucial medicines which are of the highest therapeutic importance for the provision of basic health service [20].

A recent study [21] in Orotta national referral Hospital in Asmara found that most of the bacterial isolates tested were resistant to ampicillin, ceftazidime, nitrofurantoin, 
co-trimoxazole, nalidixic acid and tetracycline. According to this study the percentage of resistance to ampicillin in E. coli was (87.5\%), Klebsiella spp (75\%), Citrobacter (100\%), Pseudomonas (81.8\%) and Salmonella (100\%) [21]. Another study conducted on the antimicrobial susceptibility of S. aureus in Eritrea found that 85\% were resistant to ampicillin [22].

The aim of this study was to investigate the antibiotic use in hospitalized patients in Halibet National Referral Hospital (HNRH) using an indicator based methodology designed by Strengthening Pharmaceutical Systems (SPS) [17].

\section{Main text \\ Methods \\ Setting}

The study was conducted at $\mathrm{HNRH}$, one of the two national referral hospitals in Asmara, Eritrea. HNRH is a 180-bed national referral and teaching hospital with Surgical, Medical, Orthopedic, Burn and Emergency wards.

\section{Study design}

A cross-sectional, retrospective study design was used to evaluate three key drug use indicators viz. hospital indicators, prescribing indicators and patient care indicator (Additional file 1: Annex S3). The methods for collecting and evaluating these indicators were adopted from the Strengthening Pharmaceutical Systems Program [17] after studying the appropriateness of the indicators to the hospital environment (see Additional file 1: Annex S1).

\section{Eligibility criteria}

Patients admitted from January 1, 2017, until December 31,2017 , and had their medication dispensed from the inpatient pharmacy, irrespective of their age, gender and diagnosis were included.

\section{Sample size and data collection}

A clinical card list of 3654 patients was prepared according to their admission dates, those admitted in January coming first and those admitted in December appearing last. We randomly picked one number $(\mathrm{X})$ from 0 to 9 , then by adding 300 to the number, a second number $(\mathrm{X}+300)$ was obtained. Starting from the second number every 300th card number was included to select 100 cases from the 3654 cases. The number of prescribing encounters to be studied were chosen based on the WHO's 1993 recommendations [7]. The complete patient chart for these samples was obtained from the record office with prior permission of the Medical Director of the hospital. The data collection forms were slightly modified and the applicable data was collected for a month i.e. March to
April 2018 using pre-defined data collection forms (see Additional file 1: Annex S1).

\section{Statistical analysis}

After checking for data completion, the necessary computations were performed according to the formulas given (Additional file 1: Annex S2). Statistical analysis such as frequencies, percentage and averages were carried out using Statistical Package for Social Sciences (IBM, SPSS Statistics for Windows, version 20. Armonk, NY: IBM Corp.).

\section{Results}

\section{Prescribing indicators}

The study found that $79 \%$ of the patients received at least one antibiotic. On average 1.29 antibiotics were prescribed per hospitalization and all $(100 \%)$ were prescribed from the EML while $97 \%$ of the antibiotics were prescribed using generic names. On average patients were treated with an antibiotic for 6.36 days (Table 1 ).

\section{Hospital indicators}

The hospital lacks a Standard Treatment Guideline and a hospital formulary. On the day of the study $87.5 \%$ of the antibiotics were available in stock and HNRH spends $25.59 \%$ of its medicines budget on antimicrobials. A key antibiotic was out of stock for 78.18 days in 2017 (Table 1).

\section{Patient care indicator}

Patients taking antibiotics, on average, stayed for 9.97 days in the hospital, with the standard deviation of 7.33 days (Table 1). Intravenous injection was the most common route of administration (81.4\%) and $77.2 \%$ of patients were given an antibiotic for less than 7 days. Ampicillin was the most commonly prescribed antibiotic and $77 \%$ of patients received only one antibiotic while $17 \%$ were treated with two antibiotics simultaneously and $6 \%$ were being treated with three antibiotics at the same time.

\section{Auxiliary indicators}

Ampicillin was the most commonly prescribed antibiotic in HNRH (Table 2). Most of the patients (77\%) had only one antibiotic prescribed (Table 2). We found 77.2\% patients took antibiotics 1 to 7 days (Table 2). Around quarter $(26 \%)$ of the patients stayed from 10 to 20 days, while $6.5 \%$ stayed longer than 21 days (Table 2 ).

\section{Discussion \\ Prescribing indicators}

We found $79 \%$ of the admitted patients had received at least one antibiotic during their hospital stay (Table 1). 
Table 1 Comparison of inpatient drug use indicators in HNRH with WHO ideal values

\begin{tabular}{|c|c|c|}
\hline Core drug use and In-patient antibiotic use indicator & Result (SD) & WHO $[13,17]$ \\
\hline Percent of hospitalization with one or more antibiotics prescribed & $79 \%$ & $20-26 \%{ }^{\mathrm{a}}$ \\
\hline Average number of antibiotics prescribed per hospitalizations & 1.29 & $1.6-1.8^{b}$ \\
\hline Percent of antibiotics from National or Hospital Formulary & $100 \%$ & $100 \%$ \\
\hline Average number of days antibiotic treatment was prescribed & $6.36(6.06)$ & - \\
\hline Percent of antibiotics prescribed by generic name & $97 \%$ & $100 \%$ \\
\hline Percentage of key antibiotics available on the day of study & $87.5 \%$ & $100 \%$ \\
\hline Average number of days that a set of key antibiotic was out of stock & 78.18 & - \\
\hline Expenditure on antimicrobials as a percentage of total hospital medicine cost & $25.59 \%$ & $20-40$ \\
\hline Average number of days of patients who received antibiotics stayed in hospital & $9.97(7.33)$ & - \\
\hline Percent of antibiotics prescribed in injection form & $81.4 \%$ & $13.4-24.1^{\mathrm{a}}$ \\
\hline
\end{tabular}

$S D$ standard deviation

a WHO optimal value for outpatient departments

${ }^{\mathrm{b}}$ WHO indicator for all medicines (including antibiotics) prescribed per encounter

Table 2 Route of administration, number per hospitalization, treatment days, most commonly prescribed antibiotics and hospital stay days in HNRH

\begin{tabular}{lll}
\hline Antibiotic treatment days & $1-7$ days & $77.2 \%$ \\
& $7-14$ days & $13.9 \%$ \\
& $15-20$ days & $2.53 \%$ \\
& $>21$ days & $3.79 \%$ \\
Number of antibiotics per hospitalization & One antibiotic & $77 \%$ \\
& Two antibiotics & $17 \%$ \\
& Three antibiotics & $6 \%$ \\
Most commonly prescribed antibiotics & Ampicillin & $42.1 \%$ \\
& Benzyl penicillin & $13.7 \%$ \\
& Gentamycin & $9.8 \%$ \\
& Cloxacillin & $8.8 \%$ \\
& Ceftriaxone & $5.9 \%$ \\
& Ciprofloxacin & $4.9 \%$ \\
& $1-10$ days & $67.5 \%$ \\
Days spent in the Hospital & $11-20$ days & $26 \%$ \\
& $>21$ days & $6.5 \%$ \\
\hline
\end{tabular}

This figure is higher than the $73.7 \%$ found by a specialty-hospital based study in Ethiopia (Table 3). Other ward-specific hospital studies reported lower antibiotic use percentages, for instance, in Ethiopia (64.7\%) [23], (73.68\%) [24] and 66\% in India [25]. A point-prevalence antibiotic use study in 11 hospitals in the Democratic Republic of Congo reported $68 \%$ of patients had received an antibiotic during their hospital stay [26] (Table 3). A study focusing on the surgical ward of HNRH in 2009 found antibiotic use prevalence to be $69 \%$, with $30 \%$ used preoperatively and $39 \%$ postoperatively [27].

This study showed that on average 1.29 antibiotics were prescribed per hospitalization (Table 1), lower than a study in the DRC in which 1.4 antibiotics were prescribed per patient [26] and much lower than the 2.1 antibiotics per patient reported in an Ethiopian hospital [28] (Table 3).

All $(100 \%)$ of the prescribed antibiotics were in the National Essential Medicines List (EML). This is because HNRH procures almost all of its medicines from one supplier, PHARMECORE, which only procures according to the EML. Therefore prescribers in HNRH are encouraged to adhere to the EML, resulting in 100\% adherence to the EML. Numerous studies reported varying percentages of EML adherence; Lesotho (79\%) [29], Pakistan (98.8\%) [4], and India (99.8\%) [9].

In $\mathrm{HNRH}$ an antibiotic was prescribed on average for 6.36 days $(\mathrm{SD}=6.06$ ) (Table 1 ). However $13.1 \%$ of patients were prescribed antibiotics longer than 10 days while $7 \%$ stayed on antibiotics longer than 14 days and $3 \%$ of patients were given an antibiotic longer than 20 days.

Overprescribing injectable medicine is considered a case of inappropriate antibiotic use [4, 30]. Parenteral was the most common route of administration consisting $81.4 \%$ of all prescribed antibiotics. This is comparable to a study in Ethiopia (82.4\%) [28] but quite higher than in the DRC (68.2\%) [26] (Table 3). Thus prescribers in HNRH need to consider switching to oral route of administration which is associated with lower treatment cost, catheter-related infections, hospital stay and burden for nursing staff [31].

\section{Hospital care indicators}

On the day of the study $87.5 \%$ of the key antibiotics were available in stock in the stores of HNRH. Similar studies done in developing countries found key antibiotics were available $72.4 \%$ in Pakistan [4] and $65.7 \%$ in Ethiopia [16] (Table 3). Our finding although better than what 
Table 3 Comparison of antibiotics use with other African countries

\begin{tabular}{|c|c|c|c|c|c|}
\hline Indicator & & $\begin{array}{l}\text { Ethiopia [8, 16, } \\
23,28,34]\end{array}$ & Sudan [35] & $\begin{array}{l}\text { DR Congo } \\
{[26]}\end{array}$ & Zambia [36] \\
\hline Percent of hospitalization with one or more antibiotics prescribed & $79 \%$ & $73.7 \%$ & $81.3 \%$ & $68 \%$ & $53.7 \%{ }^{\mathrm{a}}$ \\
\hline Average number of antibiotics prescribed per hospitalizations & 1.29 & 2.1 & $2^{b}$ & 1.4 & $2.5^{b}$ \\
\hline Generic name prescribing & $97 \%$ & $90.6 \%$ & $49.3 \%$ & NS & $56.1 \%$ \\
\hline Most commonly prescribed antibiotic & Ampicillin & Ceftriaxone & $\mathrm{NS}^{\mathrm{c}}$ & Ampicillin & Amoxicillin ${ }^{a}$ \\
\hline Parenteral route of administering antibiotics & $81 \%$ & $82.4 \%$ & $3.5 \%{ }^{\mathrm{a}}$ & $68.2 \%$ & $11.8 \%^{\mathrm{a}}$ \\
\hline Percentage of patients taking two or more antibiotics & $23 \%$ & $65 \%$ & NS & $34.9 \%$ & \\
\hline Availability of key antibiotics & $87.5 \%$ & $65.7 \%$ & $81.3 \%$ & NS & $83.3 \%$ \\
\hline Average days of antibiotic stock out per year & 78.18 & 30 & NS & NS & \\
\hline Drugs prescribed from EML & $100 \%$ & $96.6 \%$ & $57.2 \%$ & NS & $98.1 \%$ \\
\hline
\end{tabular}

a Outpatient department prescriptions

b Number of all drugs prescribed including antibiotics

c Data not stated

has been reported from Pakistan [4] and Ethiopia [16], it is less than ideal because key drugs should be available at all times [20]. Lack of access to key antibiotics forces prescribers to make less appropriate drug choices with higher costs and more risk of side effects and antibiotic resistance emergence. In HNRH key antibiotics were out of stock for an average of 78.18 days per year, much higher than the 30 days reported in Ethiopia [8] (Table 3).

\section{Patient care indicators}

The average number of hospital stay for patients in HNRH was 9.97 days (Table 1). This is much higher than the average 6 days reported by a study in a private hospital in India [25]. Furthermore, our finding shows $32.5 \%$ of the patients stayed longer than 10 days. Staying longer than 10 days is 3.086 times more likely to result in antibiotic use problems than when staying less than 10 days [31]. Prolonged hospital stay is also associated with higher treatment costs, increased risk of nosocomial infections, the emergence of resistant microorganisms and increased risk of ADR and drug-drug interaction [17, 32, 33]. We found that $6.5 \%$ of the patients in HNRH stayed longer than 20 days which could result in increased risk of antibiotic use problems. Unnecessarily longer duration of antibiotic use in HNRH needs to be addressed by developing an STG and closer therapeutic monitoring of patients taking systemic antibiotics.

\section{Limitations of the study}

The limitations which need to be considered are as follows. Firstly, the findings of this study could not be generalized to the whole of Eritrea since this was done in a single hospital. Secondly, this study was done in the inpatient department of the hospital and thus it does not reflect the outpatient prescribing patterns of the hospital.

\section{Additional file}

Additional file 1: Annex S1. Data collection forms. Annex S2. Formulas used to calculate the indicators. Annex S3. List of the three types of drug use indicators investigated in HNRH. Annex S4. Medical Director's ethical clearance.

\section{Abbreviations}

CDC: Center for Disease Control; HNRH: Halibet National Referral Hospital; DRC: Democratic Republic of Congo; DTC: Drug and Therapeutic Committee; EML: Essential Medicines List; ENLM: Eritrean National List of Medicines; I.V.: Intravenous; MoH: Ministry of Health; SPS: Strengthening Pharmaceutical Services; SPSS: Statistical Package for Social Sciences; STG: Standard Treatment Guideline; WHO: World Health Organization.

\section{Authors' contributions}

NDA and YHB designed the study. NDA collected data and did literature review. NDA, AK and YHB analyzed and interpreted the data. NDA prepared the manuscript. NDA, YHB and AK critically reviewed it. AK and NDA prepared the revised version. All authors read and approved the final manuscript.

\section{Author details}

1 School of Pharmacy, Asmara College of Health Sciences, 118-Adi Shimagle, P.O. Box 8566, Asmara, Eritrea. ${ }^{2}$ Pharmacy, Halibet National Referral Hospital, Asmara, Eritrea.

\section{Acknowledgements}

The authors would like to thank the medical director of HNRH, Dr. Yosief Yohannes for his cooperation in conducting this research. We also appreciate the help provided by the director of record office and his staff at the HNRH.

\section{Competing interests}

The authors declare that they have no competing interests.

\section{Availability of data and materials}

The datasets used and/or analyzed during the current study are available from the corresponding author upon reasonable request.

Consent for publication

Not applicable.

Ethics approval and consent to participate

Approval to conduct the study in Halibet hospital and the consent to access patients' files were obtained from the Halibet Hospital Medical Director's

Office, Dr. Yosief Yohannes, who after reading the proposal gave his approval. 


\section{Funding}

The authors did not receive any funding for this research.

\section{Publisher's Note}

Springer Nature remains neutral with regard to jurisdictional claims in published maps and institutional affiliations.

Received: 4 October 2018 Accepted: 8 December 2018

Published online: 18 December 2018

\section{References}

1. CDC. Antibiotic use in the United States. Antibiotic use in the United States, 2017: progress and opportunities. Atlanta: US Department of Health and Human Services, CDC; 2017.

2. Habte-Gabr E. Antimicrobial resistance: a global public health threat. JEMA. 2008:3:1.

3. Amane $H$, Kop P. Prescription analysis to evaluate rational use of antimicrobials. Int J Pharmacol Biol Sci. 2011;2:2.

4. Atif M, Sarwar MR, Azeem M, Umer D, Rauf A, Rasool A, et al. Assessment of WHO/INRUD core drug use indicators in two tertiary care hospitals of Bahawalpur, Punjab, Pakistan. J Pharm Policy Pract. 2016. https://doi. org/10.1186/s40545-016-0076-4

5. Pereira LP, Phillips M, Ramlal H, Teemul K, Prabhakar P. Third generation cephalosporin use in a tertiary hospital in Port of Spain, Trinidad: need for an antibiotic policy. BMC Infect Dis. 2004. https://doi. org/10.1186/1471-2334-4-59.

6. Bisht R, Katiyar A, Singh R, Mittal P. Antibiotic resistance-a global issue of concern. Asian J Pharm Clin Res. 2009;2(2):34-9.

7. WHO. How to investigate drug use in health facilities: selected drug use indicators. Geneva:WHO/DAP/93.1; 1993.

8. Sisay M, Mengistu G, Molla B, Amare F, Gabriel T. Evaluation of rational drug use based on World Health Organization core drug use indicators in selected public hospitals of eastern Ethiopia: a cross sectional study. BMC Health Serv Res. 2017. https://doi.org/10.1186/s12913-017-2097-3.

9. Aravamuthan A, Arputhavanan M, Subramaniam K, Chander SJ. Assessment of current prescribing practices using World Health Organization core drug use and complementary indicators in selected rural community pharmacies in Southern India. J Pharm Policy Pract. 2017. https://doi. org/10.1186/s40545-016-0074-6.

10. Barghouthi Achalu T, Mensa M. Retrospective drug use pattern of antibiotics in pediatric ward of Shenan Gibe hospital, Oromia Region, Ethiopia. J Antibio Res. 2017. https://doi.org/10.15744/2574-5980.1.106.

11. Otoom S, Batieha A, Hadidi H, Hasan M, Al-Saudi K. Evaluation of drug use in Jordan using World Health Organization prescribing indicators. East Mediterr Health J. 2002;8:537-43.

12. Bashrahil KA. Indicators of rational drug use and health services in Hadramout, Yemen. East Mediterr Health J. 2010;16:2.

13. El Mahalli AA. WHO/INRUD drug prescribing indicators at primary health care centres in Eastern province, Saudi Arabia. East Mediterr Health J. 2012;18:11.

14. Vooss AT, Diefenthaeler HS. Evaluation of prescription indicators established by the WHO in Getúlio Vargas-RS. BJPS. 2011;47:2.

15. Hashemi S, Nasrollah A, Rajabi M. Irrational antibiotic prescribing: local issue or global concern? EXCLI J. 2013;12:384-95.

16. Gidebo KD, Summoro TS, Kanche ZZ, Woticha EW. Assessment of drug use patterns in terms of the WHO patient-care and facility indicators at four hospitals in Southern Ethiopia: a cross-sectional study. BMC Health Serv Res. 2016;1:1. https://doi.org/10.1186/s12913-016-1882-8.

17. Strengthening Pharmaceutical Systems. How to investigate antimicrobial use in hospitals: selected indicators. Published for the U.S. Agency for International Development by the Strengthening Pharmaceutical Systems Program. Arlington: Management Sciences for Health; 2012.
18. Akinyandenu O, Akinyandenu A. Irrational use and non-prescription sale of antibiotics in Nigeria: a need for change. J Sci Innov Res. 2014:3(2):251-7.

19. WHO. Antimicrobial resistance. In: WHO, editor. Global report on surveillance. Geneva:WHO; 2014.

20. Ministry of Health. National List of Medicines. 5th ed. Asmara: Sabur Printing Press; 2005. p. 30.

21. Seyoum Y, Adgoy ET, Siele K, Elfatih M, Gebreleul N. A retrospective documentary review study of bacterial pathogen resistance to antimicrobials: a six months (July to December, 2016), at National Health Laboratory, Asmara, Eritrea. J Bacteriol Mycol Open Access. 2017;5:3.

22. Naik D, Teclu A. A study on antimicrobial susceptibility pattern in clinical isolates of Staphylococcus aureus in Eritrea. Pan Afr Med J. 2009;3:1.

23. Gube AA, Gonfa R, Tadesse T. Evaluation of antibiotic use in medical ward of Fitche district hospital, North Showa Zone, Oromia Region. Ethiopia. Adv Pharmacoepidemiol Drug Saf. 2017. https://doi.org/10.4172/21671052.1000216.

24. Sebsibie G, Gultie T. Retrospective assessment of irrational use of antibiotics to children attending in Mekelle general hospital. Sci J Clin Med. 2014. https://doi.org/10.11648/j.sjcm.20140303.14.

25. Landstedt K, Sharma A, Johansson F, Lundborg CS, Sharma M. Antibiotic prescriptions for in-patients having non-bacterial diagnosis at medicine departments of two private sector hospitals in Madhya Pradesh, India: a cross-sectional study. BMJ Open. 2017;1:1. https://doi.org/10.1136/bmjop en-2016-012974.

26. Wambale JM, Iyamba JL, Mathe DM, Kavuo SK, Takaisi-Kikuni. Point prevalence study of antibiotic use in hospitals in Butembo. Int J Med Med Sci. 2016. https://doi.org/10.5897/ijmms2016.1249.

27. Yohannes Y, Mengesha Y, Tewelde Y. Timing, choice and duration of perioperative prophylactic antibiotic use in surgery: a teaching hospital based experience from Eritrea, in. JEMA. 2009;2009:65-7.

28. Gutema G, Håkonsen H, Engidawork E, Toverud E. Multiple challenges of antibiotic use in a large hospital in Ethiopia-a ward-specific study showing high rates of hospital-acquired infections and ineffective prophylaxis. BMC Health Serv Res. 2018. https://doi.org/10.1186/s12913-018-3107-9.

29. Ntšekhe M, Hoohlo-Khotle N, Tlali M, Tjipura D. Antibiotic prescribing patterns at six hospitals in Lesotho. Submitted to the US Agency for International Development by the Strengthening Pharmaceutical Systems (SPS) Program; 2011.

30. Kallen MC, Prins JM. A systematic review of quality indicators for appropriate antibiotic use in hospitalized adult patients. Infect Dis Rep. 2017. https ://doi.org/10.4081/idr.2017.6821.

31. Tanaka A, Yano A, Watanabe S, Tanaka M, Araki H. Impact of switching from intravenous to oral linezolid therapy in Japanese patients: a retrospective cohort study. J Pharm Policy Pract. 2016. https://doi. org/10.1186/s40545-016-0087-1.

32. Yadesa TM, Gudina EK, Angamo MT. Antimicrobial use-related problems and predictors among hospitalized medical in-patients in southwest Ethiopia: prospective observational study. PLoS ONE. 2015. https://doi. org/10.1371/journal.pone.0138385.

33. Gentile I, Landolfo D, Buonomo AR, Crispo M, lula VD, Minei G, Catania MR, Borgia G. A survey on antibiotic therapy knowledge among physicians of a tertiary care and university hospital. Le Infezioni in Medicina. 2015;1:12-7.

34. Desalegn AA. Assessment of drug use pattern using WHO prescribing indicators at Hawassa University teaching and referral hospital, south Ethiopia: a cross-sectional study. BMC Health Serv Res. 2013;13:170.

35. Ahmed AM, Awad Al. Drug use practices at pediatric hospitals of Khartoum State, Sudan. Ann Pharmacother. 2010;44:1986-93.

36. Mudenda W, Chikatula E, Chambula E, Mwanashimbala B, Chikuta M, Masaninga F, Songolo P, Vwalika B, Kachimba JS, Mufunda J, Mweetwa B. Prescribing patterns and medicine use at the university teaching hospital, Lusaka, Zambia. Med J Zambia. 2016;43(2):94-102. 